\title{
A new species of the genus Epidamaeus (Acari, Oribatida, Damaeidae) from China
}

\author{
Lixia Xie ${ }^{\dagger}$, Maofa Yang ${ }^{\ddagger}$, Rong Huang ${ }^{\S}$ \\ Institute of Entomology, Guizhou University; The Provincial Key Laboratory for Agricultural Pest Management \\ of Mountainous Region, Guiyang, Guizhou, P.R. China, 550025 \\ † urn:lsid:zoobank.org:author:6E8D796C-AF36-4230-AC7B-61CD9D9E0BB7 \\ † urn:lsid:zoobank.org:author:79B3BA54-5CBD-43CD-B50C-FAABBBFA4904 \\ § urn:lsid:zoobank.org:author:687D26EC-CD49-43D5-8B02-8D62BCB67A22 \\ Corresponding author: Maofa Yang (yangmaofa@sohu.com)
}

Academic editor: Andre Bochkov | Received 30 May 2011 | Accepted 11 July 2011 | Published 15 July 2011

urn:lsid:zoobank.org:pub:D472D4A4-5EC9-428D-9C8D-B1DAEBE64F27

Citation: Xie L, Yang M, Huang R (2011) A new species of the genus Epidamaeus (Acari, Oribatida, Damaeidae) from China. ZooKeys 119: 29-36. doi: 10.3897/zookeys.119.1629

\begin{abstract}
The oribatid mite genus Epidamaeus Bulanova-Zachvatkina, 1957 from China is reviewed, and a list and key to all known species from China are provided. A new species, Epidamaeus conjungenus sp. n. is identified, and its morphological descriptions and illustrations are also given. The distinct characteristics of $E$. conjungenus sp. $\mathbf{n}$. is the coterminous ridge connected to the base of the notogastral setae. Pseudanal setae undulating attenuate, the proximal half with obvious, thorn-like barbs, the distal half smooth.
\end{abstract}

\section{Keywords}

Epidamaeus, new species, checklist, distribution.

\section{Introduction}

Oribatid mites of the genus Epidamaeus Bulanova-Zachvatkina, 1957 are known to be very diverse throughout the Northern Hemisphere, especially in Europe and North America (Bayartogtokh 2004). Most species of this genus inhabit the litter of forests,

Copyright Lixia Xie et al. This is an open access article distributed under the terms of the Creative Commons Attribution License, which permits unrestricted use, distribution, and reproduction in any medium, provided the original author and source are credited. 
mosses, decaying woods and organic soil layers, and primarily feed on decomposer or plant pathogenic fungi, therefore, they play an important role in regulation of the density of plant harmful fungi(Bayartogtokh 2000). Epidamaeus shows high taxonomic diversity in Europe and some parts of Asia. The genus comprises more than 70 species, that cosmopolitan distributed (Subías 2011). Up to now, only 6 valid species: $E$. grandjeani, E. cincinnatus, E. elegantis, E. longispinosus, E. yunnanensis, E. alticola from China were described (Wen 1990a, Wang and Norton 1993b, Enami et al. 1994, Wang and Cui 1996a, Chen et al. 2010), but the collection material from different vegetation zones of the country revealed species-richness as that in the other parts of the Palaearctic and Oriental Region. This may be related to the dynamic history of the area, which had a different climate and biota found throughout China.

In the present paper, a new species Epidamaeus conjungenus sp. n. were described from Henan Provinces. In addition, a list and key to all known Chinese species were present.

\section{Material and methods}

Measurements and descriptions are based on specimens mounted in temporary cavity slides that were studied using a light microscope equipped with a drawing attachment. Body length is measured in lateral view, from the tip of the rostrum to the posterior edge of the ventral plate. Length of leg segments, including the portion inserted into the next segment, is measured in the lateral aspect. The number of specimens measured does not always equal the number of specimens examined because structures are sometimes indiscernible under the circumstances where the specimens are not slide-mounted.

Terminology generally developed by Grandjean (1960) as applied by Norton (1979). All type specimens and other material studied are kept in Oudemans' fluid and deposited in the Institute of Entomology, Guizhou University, Guiyang, China (GUGC).

\section{Taxonomy}

Epidamaeus Bulanova-Zachvatkina, 1957

http://species-id.net/wiki/Epidamaeus

Type species: Oribata bituberculata Kulczynski, 1902 (Bulanova-Zachvatkina 1957a)

Diagnosis. Body reddish brown, medium sized, light to dark. propodolateral apophyses $P$ mostly absent, but rarely present; the formation of tubercles of Prodorsum varied: usually only $B a$ or $D a$ present, 3 pairs of tubercles $(B a, B p, D a)$ is rare present as Damaeus; $L a$ tubercle can also be present, but weak and indistinct in dorsal view, and never in combination with $B a$ (as in Kunstidamaeus); E2a and E2b missing, $V a$ and $V p$ rarely present occasionally. SS usually bristle-shaped, in shorter than ss (to 3/4 as long), bristle-shaped, mostly thin. Spinae adnata $(S a)$ usually present (subgen. Epi- 
damaeus) or absent (subgen. Akrodamaeus); The length of legs medium to long; Tibiae I-IV without setae $d$; Setal mostly formula of genua I-IV: 4-4-3-3, rarely 4-4-4-4; Associated setal (setae $d$ ) formula of genua I-IV: 1-1-1-0; Setal formula of trochanters I-IV: 1-1-2-1; Additional ventral seta $v 2$ " on I and IV missing. $6 \mathrm{~g}, 1 \mathrm{ag}, 2$ on, 3 ad. (Weigmann 2006)

Distribution. Palaearctic, Oriental, Nearctic, Neotropical and Australian regions.

\section{Species of genus Epidamaeus from China}

\section{E. alticola Wang \& Cui, 1996}

Epidamaeus alticola Wang and Cui 1996a: 321; 1996b: 258.

Material examined. $5 \hat{\jmath} \hat{\jmath}, 49+$, China, Qinghai Prov., Xining City, Huzhu National Geological Park $\left(36^{\circ} 57^{\prime} 11^{\prime \prime} \mathrm{N}, 102^{\circ} 28^{\prime} 55^{\prime \prime} \mathrm{E}\right)$, from litter under Pteridophytes, 2384 m a.s.l., 23 August 2009, coll. Lixia Xie (GUGC)

Distribution. China (Qinghai).

\section{E. cincinnatus Wang \& Norton, 1993}

E. cincinnatus Wang and Norton 1993b: 312; Wang et al. 2000: 323.

Material examined. 11ภึ, $6 q$,, China, Hebei Prov., Chengde City, Mt. Wuling $\left(40^{\circ} 36^{\prime} 50^{\prime \prime} \mathrm{N}, 117^{\circ} 28^{\prime} 57^{\prime \prime} \mathrm{E}\right)$, from litter under birch, $1362 \mathrm{~m}$ a.s.l., 25 August 2010, coll. Lixia Xie (GUGC)

Distribution. China (Beijing).

\section{E. elegantis Wang \& Norton, 1993}

E. elegantis Wang and Norton 1993b: 316-318; Wang et al. 2000: 311.

Material examined. $6{ }^{\lambda} \sigma^{\lambda}, 3$ 우, China, Fujian Prov., Wuyishan City, Mt. Wuyi $\left(27^{\circ} 45^{\prime} 19^{\prime \prime N}, 118^{\circ} 02^{\prime} 56 " \mathrm{E}\right)$, from litter under the chestnut trees , $278 \mathrm{~m}$ a.s.l., $4 \mathrm{Au}-$ gust 2008, coll. Zehong Meng (GUGC)

Distribution. China (Fujian, jiangxi).

\section{E. grandjeani Bulanova-Zachvatkina, 1957}

E. grandjeani Bulanova-Zachvatkina 1957: 1794-1796; Wen 1990a: 119; Wang et al. 2000: 256.

Distribution. China (Jilin), Russia (Tatarstan).

\section{E. longispinosus Wang \& Norton, 1993}

E. longispinosus Wang \& Norton, 1993b, p. 314-316; Wang, Cui \& Liu, 2000, p. 310-311.

Material examined. $4 \hat{\jmath}, 5 ㅇ+$, China, Fujian Prov., Wuyishan City, Mt. Wuyi $\left(27^{\circ} 45^{\prime} 24 " \mathrm{~N}, 118^{\circ} 02^{\prime} 46^{\prime \prime} \mathrm{E}\right)$, from litter of coniferous forest, $263 \mathrm{~m}$ a.s.l., 5 August 2008, coll. Zaihua Yang (GUGC)

Distribution. China (Fujian, Jiangxi). 


\section{E. yunnanensis Enami, Aoki \& Hu, 1994}

E. yunnanensis Enami et al. 1994: 43-46; Aoki et al. 2000: 6.

Material examined. $2 \hat{\jmath} \widehat{\jmath}, 3+q$, China, South of Guizhou Prov., Maolan National Nature Reserve $\left(25^{\circ} 19^{\prime} 26^{\prime \prime} \mathrm{N}, 107^{\circ} 55^{\prime} 59^{\prime \prime E}\right)$, from litter under Podocarpus, $819 \mathrm{~m}$ a.s.l., 16 Sep. 2007, coll. Zaihua Yang (GUGC); 7ðึ, 6우, China, Yunnan Prov., Dali City, Mt. Cang (2538'38"N, 10009'53"E), from litter under the pine, $1950 \mathrm{~m}$ a.s.1., 18 December 2008, coll. Yi Yan (GUGC)

Distribution. China (Yunnan, Guizhou).

\section{Key to species from China}

1 Propodolateral apophysis $(P)$ present, having tubercles $(L a)$

E. yunnanensis Enami, Aoki \& $\mathrm{Hu}$

- $\quad$ Propodolateral apophysis $(P)$ absent, not having tubercles $(L a)$................. 2

2 Notogastral setae cincinal, genital seta $g_{6}$ far from $g_{5}$

E. cincinnatus Wang \& Norton

- $\quad$ Notogastral setae not cincinal, genital setae normal for genus ....................3

3 Sensillus (ss) aciculiform, aggenital seta (ag) lies between Anal aperture and genital aperture E. elegantis Wang \& Norton

- $\quad$ Sensillus (ss) rod-like or flagellate, aggenital seta $(\mathrm{ag})$ normal for genus........4

4 Sensillus (ss) rod-like, seta $c_{1}$ longer than other notogastral setae E. alticola Wang \& Cui

- $\quad$ Sensillus (ss) flagellate, seta $c_{1}$ not longer than other notogastral setae..........5

$5 \quad$ Notogastral setae leafy, Spinae adnatae rod-like

E. grandjeani Bulanova-Zachvatkina

- $\quad$ Notogastral setae not leafy, Spinae adnatae not rod-like 6

6 Coterminous ridge connected to the base of the notogastral setae; Spinae adnatae not long and spinous.

E. conjungenus sp. n.

- $\quad$ Coterminous ridge not connected to the base of the notogastral setae; Spinae adnatae long and spinous.....

E. longispinosus Wang \& Norton

\section{Epidamaeus conjungenus sp. $\mathbf{n}$.}

urn:lsid:zoobank.org:act:7B87D6F6-BE4F-408C-8451-A0500B9F4A27

http://species-id.net/wiki/Epidamaeus_conjungenus

Fig. 1

Material examined. Holotype (female in Oudemans' fluid ), China: Luoyang city, Mt. Baiyun $\left(34^{\circ} 23^{\prime} 25.18^{\prime \prime} \mathrm{N}, 11^{\circ} 01^{\prime} 23.15^{\prime} \mathrm{E}\right)$, Henan province, from litter, $2100 \mathrm{~m}$ a.s.l., 16 Aug. 2008, coll. Li-xia Xie. Paratypes. Five adults (2 males, 3 females), with same data as holotype.

Etymology. The specific name "conjunctus" is from Latin, and refers to the conjunct ridge. 


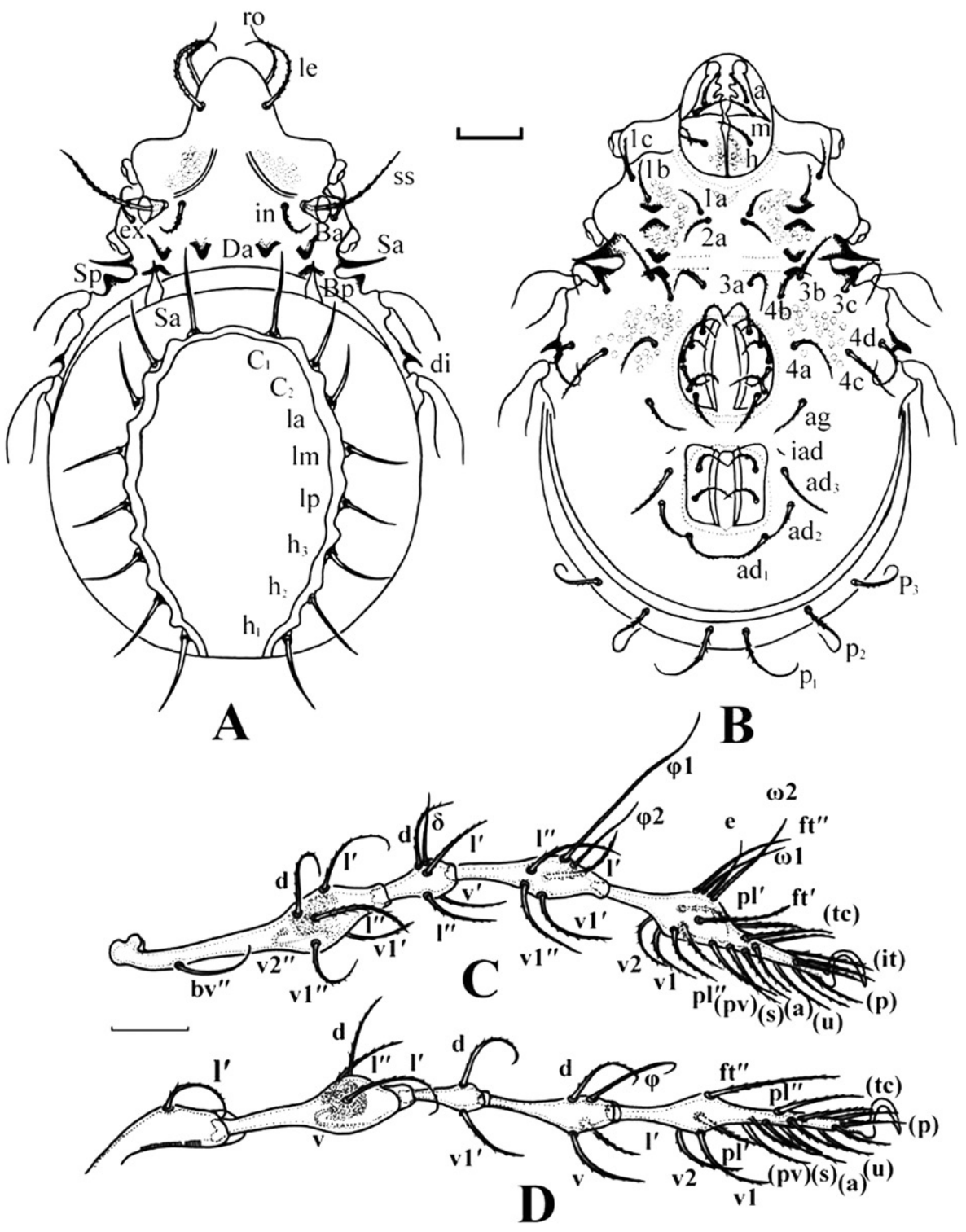

Figure I. Epidamaeus conjungenus sp. n. A adult, dorsal view $(100 \mu \mathrm{m})$ B adult, ventral view $(100 \mu \mathrm{m})$ C leg I $(100 \mu \mathrm{m}) \mathbf{D}$ leg IV $(100 \mu \mathrm{m})$.

Diagnosis. Prodorsal tubercles $D a, B a, B p$ present. Sensillus smooth, short, with conspicuous bars. $S a$ triangular, long and acuminate. $S p$ small, triangular. Enantiophysis $E 2$ and $V$ present. $V p$ bearing seta $3 b$. The setae of notogaster acuminate, radially directed. Leg setation as follows, femora 7-6-4-4; genua 4-4-3-2; tibiae 4-4-3-3; tarsi 21-18-18-15. 
Dimensions. Body length 913 (holotype), 913- 932 (mean 924, 6 paratypes); body width 605 (holotype), 602- 623 (mean 610, 6 paratypes). Males slightly smaller than females: body length of males holotype and 2 paratypes) 886- 902 (mean 894), body width of males 584- 592 (mean 588); body length of females (4 paratypes) 906914(mean 910), body width of females (4 paratypes) 596- 624 (mean 610).

Integument. Microtuberculate on all enantiophyses and apophyses, rostrum, lateral prodorsum and around leg acetabula. Cerotegument granules, thick, dense on most of body and legs, except digital part of tarsi. Notogaster with exuvial scalps, legs segments and lateral part of body with dense fungus micelles and adherent debris.

Prodorsum. Tubercles $D a$ and $B p$ well developed, broadly rounded; $B a$ represented as high ridge. Propodolateral apophysis $(P)$ absent. A ridge presents the side of prodorsum. Setae ro $(175-183 \mu \mathrm{m})$ and le $(216-221 \mu \mathrm{m})$ long, smooth, with conspicuous barbs; mutual distance of pairs le slightly less than that of ro (1.0:1.1). Interlamellar setae $(96-104 \mu \mathrm{m})$, dark brown, with small barbs. Exobothridial setae $(94-98 \mu \mathrm{m})$ smooth, relatively tenuous, attenuate. Sensillus $(225-232 \mu \mathrm{m})$, with conspicuous barbs, undulating attenuate. Comparative length of prodorsal setae: $e x<i n<r o<l e<s s$.

Notogaster. Almost circular, slightly longer than wide. Anterior and posterior margins broadly rounded in dorsal view. Spinae adnatae large, directed anterolaterad in dorsal view, distance between their bases approximately equal to that between tubercles $B p$. Notogastral setae of $c$-, $l$ - and $h$ - series inserted on distinct tubercles. Setae relatively smooth, brown, acuminate. Comparative length: $l m<l p<l a=h_{3}<h_{2}<h_{1}=c_{1}=c_{2}$. The respective lengths: $88-94 \mu \mathrm{m}, 107-110 \mu \mathrm{m}, 137-142 \mu \mathrm{m}, 147-154 \mu \mathrm{m}$ and 167-172 $\mu \mathrm{m}$. Setae $c_{1}, c_{2}$ and $l a$ directed anterodorsad, other setae radially directed. A conjoint ridge connected to base of all notogastral setae. Mutual distance of setae $c_{2}$ twice that of $c_{1}$. Pseudanal setae undulating attenuate, the proximal half with obvious, thorn-like barbs, the distal half smooth. Comparative length: $p s_{1}>p s_{2}>p s_{3}$.

Ventral region. Epimere I with medial pit and associated groove. Enantiophyses $E_{2}$ and $V$ well developed, broadly triangular in ventral view. Tubercle $V p$ bearing epimeral seta $3 b$. Parastigmatic tubercle $S a$ long, acuminate and triangular. $S p$ triangular, distinct in ventral view. Length of lateral aspect $S p$ twice as broad as $S a$. Discidium acuminate, smaller than $S p$, directed posterolaterad. Ventral setae faintly barbed. Setae $3 c$, $4 d$ very long, flagelliform. Epimeral setation: 3-1-3-4. Anogenital region normal, seta $a d_{3}$ close to anal valves. Fissure iad minute, represented by small, inconspicuous pore in lateral corner of valve. Anal aperture appreciably equal to genital aperture.

Gnathosoma. Infracapitular mentum slightly wider than long, without noticeable microtubercles. Hypostomal setae $a, h$ and $m$ thin, slightly barbed; seta $a$ relatively short. Chelicera rather strong, fixed and movable digits with three blunt teeth; setae $c h a$ and $c h b$ conspicuously barbed. Palpal setation: $0-2-1-3-8$ including solenidion $\omega$.

Legs. Relative lengths (I-IV): 1: 0.84: 0.95: 1.1. Leg IV 1.1 times ventral body length; Femur IV 1.44 times length of trochanter IV. Formulae of leg setation and solenidia: I (1-7- 4- 4- 21) [1-2-2], II (1-6-4-4-18) [1-1-2], III (2-4-3-3-18) [1-1-0], IV (1-4-3-3-15) [0-1-0]; Each solenidion on genu I - III coupled with a respective seta 
$d$, seta $d$ longer than solenidion on genu I-III. Solenidion $\varphi_{1}$ on tibia I flagelliform, and 2.2 times longer than $\varphi_{2}$.

Distribution. Known only from the type locality.

Table I. Leg setation and solenidia of Epidamaeus conjungenus sp. n.

\begin{tabular}{l|l|l|l|l|l}
\hline Legs & Trochanter & Femur & Genu & Tibia & Tarsus \\
\hline I & $v$ & $\begin{array}{l}d, l, l^{\prime}, v_{1}^{\prime} v_{1}^{\prime \prime} \\
b v^{\prime}, v_{2}^{\prime}\end{array}$ & $d, \sigma, l,(v)$ & $\begin{array}{l}\varphi_{1}, \varphi_{2}, l, l^{\prime}, \\
(v)\end{array}$ & $\begin{array}{l}f t^{\prime}, f t^{\prime}, p l, p l^{\prime},(v), \omega_{1}, \omega_{2}, \varepsilon, \\
(p v),(t c),(i t),(p),(u),(a), s\end{array}$ \\
\hline II & $v$ & $\begin{array}{l}d, l, l^{\prime}, b v^{\prime}, \\
(v)\end{array}$ & $d, \sigma, l^{\prime},(v)$ & $\varphi,(l),(v)$ & $\begin{array}{l}f t^{\prime}, f t^{\prime},(v), \omega_{1}, \omega_{2},(p v),(t c), \\
(i t),(p),(u),(a), s\end{array}$ \\
\hline III & $l, v^{\prime}$ & $d, l, e v^{\prime}, v^{\prime}$ & $d, \sigma, l, v^{\prime}$ & $d, \varphi, l, v^{\prime}$ & $\begin{array}{l}f t, v^{\prime}, p v^{\prime \prime}, p v^{\prime},(t c),(i t),(p), \\
(u),(a), s\end{array}$ \\
\hline IV & $v$ & $d, l, e v^{\prime}, v^{\prime}$ & $d, l, v^{\prime}$ & $\varphi, l,(v)$ & $\begin{array}{l}f t^{\prime},(v),(p v),(t c),(p),(u), \\
(a), s\end{array}$ \\
\hline
\end{tabular}

Remarks. Epidamaeus conjungenus sp. n. can be readily distinguished from most of known species of Epidamaeus by the coterminous ridge connected to the base of the notogastral setae. Pseudanal setae undulating attenuate, the proximal half with obvious, thorn-like barbs, the distal half smooth. Parastigmatic tubercle $S a$ very long, acuminate, Discidium $(d i)$ acuminate. The strong Spinae adnatae $(S a)$. The Prodorsum of this new species is somewhat similar to E. verrucatus described by Enami and Fujikawa (1989), but the setae of notogaster of new species are smooth, and lack of Propodolateral apophysis $(P)$ and present tubercles $D a$ and $B p$.

\section{Acknowledgements}

We would like to express our heartfelt thanks to Roy A. Norton (College of Environmental Science and Forestry, State University of New York, Forestry Drive, Syracuse, New York, U.S.A) and Sergey G. Ermilov (Laboratory of Entomology, Center of Independent Examinations-NN, Nizhniy Novgorod, Russia) for their encouragement to our research and fervidly sending documents. Thanks are also due to all the people who participated in the specimens' collection, for their friendly help and eager cooperation.

\section{Reference}

Aoki J, Yamamoto Y, Hu SH (2000) A checklist of oribatid mites of Yunnan Province in China (Acari, Oribatida). In: Aoki J, Yin WY (Eds) Taxonomical studies on the soil fauna of yunnan province in southwest China. Tokai University Press, Tokyo, 36 pp. 
Bayartogtokh B (2000) Two Species of Damaeid Mites (Acari: Oribatida: Damaeidae) from Mongolia, with notes on distribution of the genera Epidamaeus and Dyobelba. Biogeography 2: 67-79.

Bayartogtokh B (2004) Oribatid mites of the Genus Epidamaeus (Acari: Oribatida: Damaeidae) from Eastern Mongolia. J. Acarol. Soc. Jpn 13(2): 161-168. doi:10.2300/acari.13.161

Bulanova-Zachvatkina EM (1957a) Epidamaeus grandjeani Bul.-Zachv., gen. et sp. nov. (Acariformes, Oribatei) from Kuril Islands. Rev. Ent. URSS 36: 547-552.

Bulanova-Zachvatkina EM (1957) Oribatid mites Damaeidae Berl. Genus Epidamaeus, Gen. N. (Acariformes, Oribatei). Part II. Zoological magazine, xxxvi, 12: 1792-1801 [in Russian]

Chen J, Liu D, Wang HF (2010) Oribatid mites of China: a review of progress, with a checklist. In: Zhang Z-Q, Hong X-Y, Fan Q-H (Eds) Xin Jie-Liu Centenary: Progress in Chinese Acarology. Zoosymposia 4. Magnolia Press, 199 pp.

Enami Y, Aoki J, Hu SH (1994) Oribatid mites from tropical forests of Yunnan Province in China. IV. Family Damaeidae. Proceeding of the Japanese Society of Systematic Zoology 52: 43-46.

Grandjean F (1960) Damaeus arvernensis n sp. (Oribate). Acarologia 2: 250-275.

Norton RA (1979) Damaeidae (Acari: Oribatei) collected by the Hungarian Soil Zoological Expeditions to South America. Folia Ent. Hung. 32: 55-64.

Subías LS (2004) Listado sistemático, sinonímico y biogeográfico de los ácaros oribátidos (Acariformes: Oribatida) del mundo (excepto fósiles). Graellsia 60(número extraordinario): 3-305. [Online version actualized in April 2009] http://www.ucm.es/info/zoo/Artropodos/Catalogo.pdf

Wang HF, Norton RA (1993b) Three new species of Epidamaeus from China (Acari: Oribatida: Damaeidae). Acta Zootaxonomica Sinica 18(3): 312-321 [in Chinese with English abstract]

Wang HF, Cui YQ (1996a) Acari: Oribatida. In: Huang FS (Eds) Insects of the KarakorumKunlun Mountains. Science Press, Beijing, 321-328.

Wang HF, Cui YQ (1996b) Acari: Oribatida. In: Wu SG, Feng ZJ (Eds) The Biology and Human Physiology in the Hoh Xil Region. Science Press, Beijing, 258-264. [in Chinese with English abstract]

Wang HF, Cui YQ, Liu YH (2000) Acari: Oribatida. In: Huang BK (Eds) Fauna of Insects in Fujian Province of China, Vol. 9. Fujian Science and Technology Publishing House, Fuzhou, 296-323. [in Chinese with English abstract]

Wang HF, Hu SH, Yin SG (2000) The oribatid fauna and distribution in different zones in China. In: Yin WY et al. (Eds) Soil Animals of China. Science Press, Beijing, 251-265. [in Chinese]

Weigmann G (2006) Hornmilben (Oribatida). Die Tierwelt Deutschlands. 76 Tiel. Goecke and Evers, Keltern, 520 pp.

Wen ZG (1990a) Preliminary investigation of soil oribatid mites in Jilin Province. Journal of Northeast Normal University (Suppl.): 115-124. [in Chinese] 